\title{
Permeation characteristics of tetracyclines in parallel artificial membrane permeation assay II: Effect of divalent metal ions and mucin
}

\author{
Sachika Yamauchi, Daisuke Inoue, Kiyohiko Sugano* \\ Molecular Pharmaceutics Lab., College of Pharmaceutical Sciences, Ritsumeikan University, 1-1-1, Noji-higashi, \\ Kusatsu, Shiga 525-8577, Japan
}

*Corresponding Author: E-mail: suganok@fc.ritsumei.ac.jp; Tel.: +81-77-561-2773

Received: February 27, 2020; Revised: April 05, 2020; Published: May 01, 2020

\begin{abstract}
The bioavailability of tetracyclines is markedly decreased when co-administered with antacids, milk, or food containing $\mathrm{Ca}^{2+}$. Previously, it was suggested that the effective intestinal permeation of tetracycline (TC) was decreased due to $\mathrm{Ca}^{2+}$ linked mucin binding in the mucosal side. In the present study, we investigated the effect of $\mathrm{Ca}^{2+}, \mathrm{Mg}^{2+}$, and mucin on the membrane permeation of six tetracyclines (TC, oxytetracycline (OTC), minocycline (MINO), doxycycline (DOXY), demeclocycline (DMCTC), and chlortetracycline (CTC)). The membrane permeability values $\left(\mathrm{P}_{\mathrm{e}}\right)$ of tetracyclines were measured by the parallel artificial membrane permeation assay (PAMPA) using soybean lecithin - decane (SL-PAMPA) and octanol (OCT-PAMPA) membranes. In SL-PAMPA, $\mathrm{Ca}^{2+}$ markedly decreased the $\mathrm{P}_{\mathrm{e}}$ values of all tetracyclines. In OCT-PAMPA, $\mathrm{Ca}^{2+}$ increased the $\mathrm{P}_{\mathrm{e}}$ values of TC, CTC, and DMCTC, but not DOXY, OTC, and MINO. $\mathrm{Mg}^{2+}$ decreased the $\mathrm{P}_{\mathrm{e}}$ values of all tetracyclines in both SL-PAMPA and OCT-PAMPA (except for CTC in OCT-PAMPA). The addition of mucin had little or no effect in all cases. In contrast to the previously suggested mechanism, the results of the present study suggested that $\mathrm{Ca}^{2+}$ chelate formation decreased the membrane permeation of tetracyclines, irrespective of $\mathrm{Ca}^{2+}$ linked mucin binding. Molecular speciation analysis suggested that the permeation of TC - metal chelates was negligibly small in SL-PAMPA.
\end{abstract}

(C)2020 by the authors. This article is an open-access article distributed under the terms and conditions of the Creative Commons Attribution license (http://creativecommons.org/licenses/by/4.0/).

\section{Keywords}

artificial membrane; permeability; phospholipid; tetracycline; metal; cation; mucin

\section{Introduction}

Co-administration of multivalent metal ions reduces the bioavailability of various drugs, such as tetracyclines, fluoroquinolones, HIV-integrase inhibitors, and platelet-stimulating agents [1-4]. For example, the bioavailability of tetracyclines is markedly decreased when co-administered with antacids, milk, and food containing $\mathrm{Ca}^{2+}[4-10]$. It is generally accepted that chelate formation between tetracycline (TC) and $\mathrm{Ca}^{2+}$ is behind the observed decrease in the bioavailability of tetracyclines [11-16]. Chelate formation of tetracyclines has been extensively investigated (Ref. [17] and references therein). However, the exact mechanism of the $\mathrm{Ca}^{2+}$ effect on the bioavailability of tetracyclines has not been clear. 
Several ex-vivo and in-situ studies have shown that divalent metal ions, such as $\mathrm{Ca}^{2+}, \mathrm{Mg}^{2+}$, and $\mathrm{Fe}^{2+}$, reduce the intestinal wall permeation of tetracyclines [18-22]. In 1968, Kakemi et al. investigated the effect of $\mathrm{Ca}^{2+}$ on the effective intestinal wall permeation of tetracycline (TC) using the rat small intestine $[21,22]$. They also measured the isopentanol - buffer partition coefficient as a surrogate of passive transcellular membrane permeability without the interference from mucin. They found that $\mathrm{Ca}^{2+}$ decreased the effective intestinal wall permeation of TC in the rat ex-vivo experiment, but increased the partition coefficient of TC. They also found that TC bound to the intestinal mucin layer in the presence of $\mathrm{Ca}^{2+}$. Based on these observations, they suggested that $\mathrm{Ca}^{2+}$ linked mucin binding decreased the TC concentration available for membrane permeation, resulting in a decrease in the effective intestinal wall permeation. Schumacher and Linn also reported that $\mathrm{Ca}^{2+}$ increased the transfer rate of TC from the aqueous phase to the octanol phase [23]. However, it is questionable whether these alcohol systems could be a good surrogate model for investigating the effect of divalent metal ions on the membrane permeation of drugs. Since divalent metal ions may affect cellular integrity, mucin-free cell-based systems such as Caco-2 have rarely been used to examine the effects of multivalent metal ions on membrane permeation [24,25].

The parallel artificial membrane permeation assay (PAMPA) has been widely used to assess the passive membrane permeation of a drug [26-29]. Phospholipid-based artificial membranes are most commonly used with PAMPA. PAMPA permeability correlates with the in vivo and cellular permeation of drugs better than the octanol-buffer partition coefficient $[27,28]$. Recently, we reported the permeation characteristics of tetracyclines in a phospholipid-based PAMPA [30]. Only a weak correlation was observed between the PAMPA permeability $\left(P_{\mathrm{e}}\right)$ and the octanol-buffer partition coefficients ( $\left.\log D_{\text {oct }}\right)$ for tetracyclines, suggesting that chemoselectivity differs between these systems. However, the effects of divalent metal ions on the PAMPA permeation of tetracyclines have been unknown.

The purpose of the present study was to investigate the effect of $\mathrm{Ca}^{2+}, \mathrm{Mg}^{2+}$, and mucin on the phospholipid-based PAMPA permeation of tetracyclines. Six tetracycline derivatives were used in this study (Figure 1). The physicochemical properties of these tetracyclines have been summarized in Table 1 [31-33].

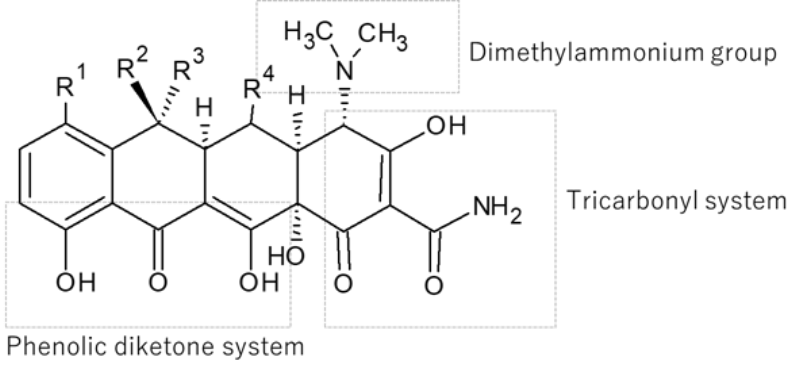

\begin{tabular}{ll|lll} 
Name & $\mathrm{R}^{1}$ & $\mathrm{R}^{2}$ & $\mathrm{R}^{3}$ & $\mathrm{R}^{4}$ \\
\hline Chlortetracycline (CTC) & $\mathrm{Cl}$ & $\mathrm{OH}$ & $\mathrm{CH}_{3}$ & $\mathrm{H}$ \\
Demeclocycline (DMCTC) & $\mathrm{Cl}$ & $\mathrm{OH}$ & $\mathrm{H}$ & $\mathrm{H}$ \\
\hline Doxycycline (DOXY) & $\mathrm{H}$ & $\mathrm{H}$ & $\mathrm{CH}_{3}$ & $\mathrm{OH}$ \\
Minocycline (MINO) & $\mathrm{NMe}_{2}$ & $\mathrm{H}$ & $\mathrm{H}$ & $\mathrm{H}$ \\
\hline Oxytetracycline (OTC) & $\mathrm{H}$ & $\mathrm{OH}$ & $\mathrm{CH}_{3}$ & $\mathrm{OH}$ \\
Tetracycline (TC) & $\mathrm{H}$ & $\mathrm{OH}$ & $\mathrm{CH}_{3}$ & $\mathrm{H}$
\end{tabular}

Figure 1. Chemical structures of tetracyclines

\section{Experimental}

\section{Materials}

Tetracycline hydrochloride (TC), decane, calcium dichloride, magnesium dichloride, octanol, pig stomach mucin, and $8 \mathrm{M} \mathrm{NaOH}$ were purchased from Wako Pure Chemical Industries, Ltd (Osaka, Japan). 
Oxytetracycline hydrochloride (OTC), minocycline hydrochloride (MINO), and doxycycline hyclate (DOXY) were purchased from TCI (Tokyo, Japan). 2-Morpholinoethanesulfonic acid (MES) was purchased from Dojindo laboratories (Tokyo, Japan). Demeclocycline hydrochloride (DMCTC) and chlortetracycline hydrochloride (CTC) were purchased from LKT Labs, Inc (MN, USA). Soybean lecithin (SLP-white) was provided by Tsuji Oil Mills co., Ltd (Mie, Japan).

Table 1. Physicochemical properties of tetracyclines

\begin{tabular}{|c|c|c|c|c|}
\hline & $M_{\mathrm{w}}$ & $\mathrm{p} K_{\mathrm{a}}$ & $\log D_{\text {oct }}(\mathrm{pH} 6.5)^{\mathrm{a}}$ & $\mathrm{p} K_{\mathrm{a}}$ Ref. \\
\hline \multirow[t]{2}{*}{ Chlortetracycline } & 479 & $3.3,7.6,9.3$ & -0.88 & {$[31]^{b}$} \\
\hline & & $3.25,6.72,8.84$ & & {$[32]^{c}$} \\
\hline Demeclocycline & 465 & $3.4,7.4,9.4$ & -0.67 & {$[31]^{b}$} \\
\hline \multirow[t]{2}{*}{ Doxycycline } & 444 & $3.0,8.0,9.2$ & -0.08 & {$[31]^{\mathrm{b}}$} \\
\hline & & $3.50,7.25,9.58$ & & {$[32]^{c}$} \\
\hline Minocycline & 457 & $2.8,5.0,7.8,9.5$ & 0.20 & {$[33]^{d}$} \\
\hline \multirow[t]{2}{*}{ Oxytetracycline } & 460 & $3.2,7.5,8.9$ & -0.96 & {$[31]^{b}$} \\
\hline & & $3.53,7.25,9.58$ & & {$[32]^{c}$} \\
\hline \multirow[t]{2}{*}{ Tetracycline } & 444 & $3.3,7.8,9.6$ & -1.09 & {$[31]^{b}$} \\
\hline & & $3.35,7.29,9.88$ & & {$[32]^{c}$} \\
\hline
\end{tabular}

\section{PAMPA assay}

The PAMPA sandwich was consisted of a 96 well filter plate (hydrophobic PVDF, $0.45 \mu \mathrm{m}$ ) and a PAMPA acceptor plate (Merck Millipore, MA, USA). Before forming the PAMPA sandwich, the bottom (acceptor) plate was filled with $300 \mu \mathrm{L}$ of a $50 \mathrm{mM}$ MES buffer ( $\mathrm{pH}$ 6.5). The filter of the top (donor) compartment was coated with $5 \mu \mathrm{L}$ of a $10 \%$ soybean lecithin (SL) - decane solution or octanol. A drug solution $(0.5 \mathrm{mM}$, $200 \mu \mathrm{L}$ ) with or without a divalent metal ion $(5 \mathrm{mM})$ and/or mucin $(1 \%)$ in the same buffer was added to the donor compartment. The PAMPA sandwich was then incubated for $3 \mathrm{~h}$ at $37{ }^{\circ} \mathrm{C}$. After incubation, $150 \mu \mathrm{L}$ of both the donor and acceptor solutions were transferred to a UV plate. The concentrations of tetracyclines were measured at $360 \mathrm{~nm}$. The PAMPA permeability $\left(P_{\mathrm{e}}\right)$ was calculated by the following equation [34].

$$
\begin{aligned}
& P_{\mathrm{e}}=-\frac{2.303 V_{\mathrm{D}}}{A t}\left(\frac{1}{1+r_{\mathrm{v}}}\right) \log \left(-r_{\mathrm{v}}+\left(\frac{1+r_{\mathrm{v}}}{1-R}\right) \frac{C_{\mathrm{D}}(t)}{C_{\mathrm{D}}(0)}\right) \\
& R=1-\frac{C_{\mathrm{D}}(t)}{C_{\mathrm{D}}(0)}-\frac{1}{r_{\mathrm{v}}} \frac{C_{\mathrm{A}}(t)}{C_{\mathrm{D}}(0)} \\
& r_{\mathrm{v}}=\frac{V_{\mathrm{D}}}{V_{\mathrm{A}}}
\end{aligned}
$$

where $P_{\mathrm{e}}$ is the effective permeation coefficient $(\mathrm{cm} / \mathrm{s}), A$ is the filter surface area $\left(0.266 \mathrm{~cm}^{2}\right), V_{\mathrm{D}}$ and $V_{\mathrm{A}}$ are the volumes $(\mathrm{mL})$ in the donor and acceptor phase, $t$ is the incubation time, $C_{D}(t)$ is the concentration of a drug in the donor phase at time $t, R$ is the membrane retention factor, and $r_{v}$ is the volume ratio. We confirmed that the phospholipid - decane membrane is stable during the experimental period (no leakage of impermeable substrate) (data not shown). 


\section{Results and discussion}

Previously, we reported that the $P_{\mathrm{e}}$ value of TC was markedly affected by the composition of phospholipids in PAMPA [30]. In this study, a soybean lecithin (SL, $10 \%$ ) - decane membrane (SL-PAMPA) was used because it most likely mimics the intestinal membrane [34]. The soybean lecithin contained phosphatidylcholine (24-32 \%), phosphatidylethanolamine (20-28\%), phosphatidylinositol (12-20\%), phosphatidic acid (8-15\%), and lysophosphatidylcholines (1-5 \%) (based on the product information provided by the manufacturer). In addition, an octanol membrane (OCT-PAMPA) $[35,36]$ was also used because $\mathrm{Ca}^{2+}$ was reported to increase the $\log D_{\text {oct }}$ of TC [23]. Since $\mathrm{Ca}^{2+}$ interacts with phosphate and citrate ions, MES buffer was used in this study. The concentration of $\mathrm{Ca}^{2+}$ was set to $5 \mathrm{mM}$ based on the standard of the daily intake in food $(600 \mathrm{mg})$ [37] and the gastrointestinal fluid volume in the fed state [38]. We previously reported that the $P_{\mathrm{e}}$ value of TC in SL-PAMPA was not affected by the ionic strength up to 2 $\mathrm{mol} / \mathrm{L}$ (adjusted by $\mathrm{NaCl}$ ) [34].

In SL-PAMPA, $\mathrm{Ca}^{2+}$ and $\mathrm{Mg}^{2+}$ markedly decreased the $P_{\mathrm{e}}$ values of all tetracyclines investigated in this study, whereas mucin showed little or no effect (Figure 2). These results suggest that, in contrast to the previous suggestion based on the alcohol-water partition coefficient [21-23], $\mathrm{Ca}^{2+}$ chelate formation decrease the membrane permeation of tetracyclines, irrespective of $\mathrm{Ca}^{2+}$ linked mucin binding.

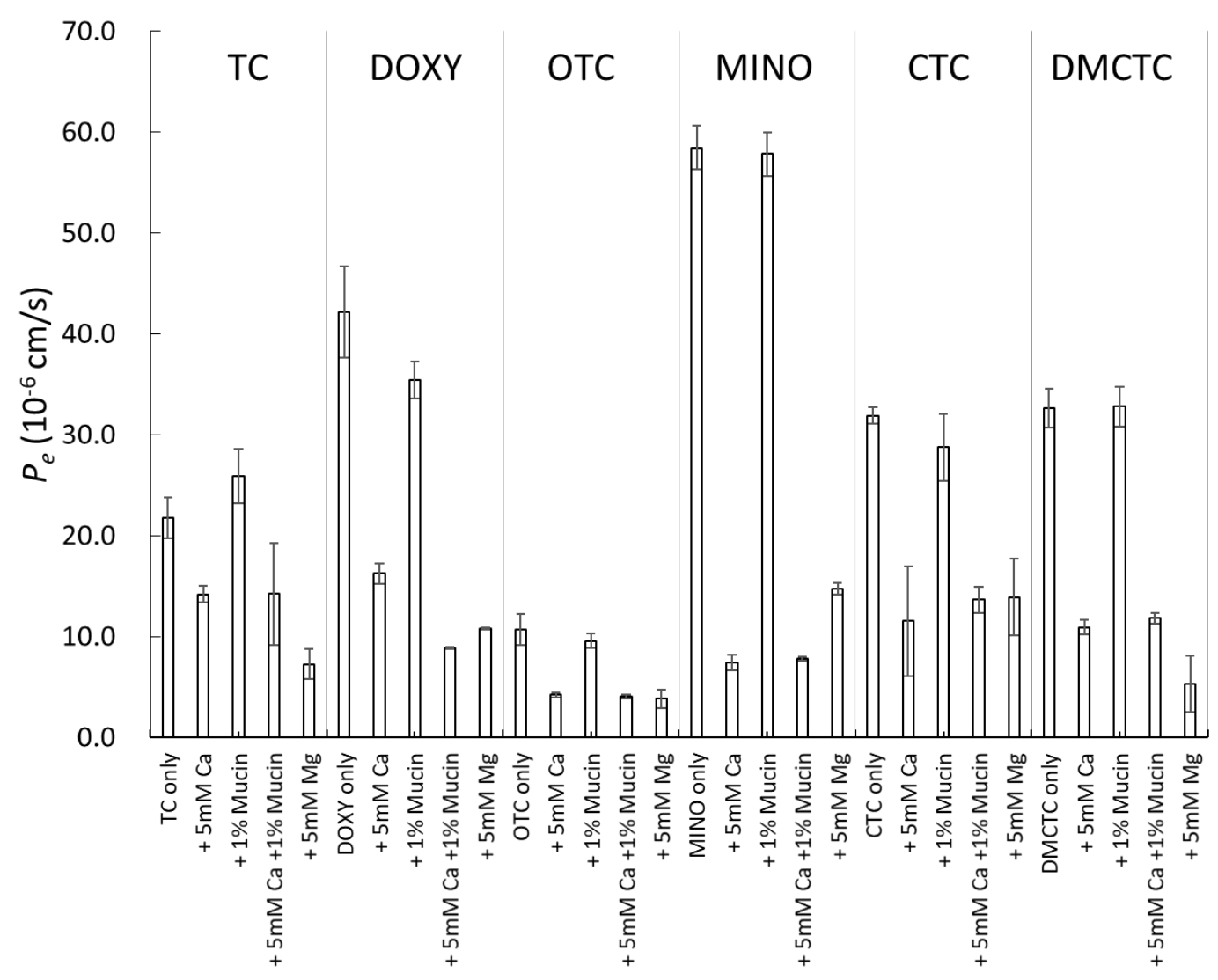

Figure 2. Effect of additives on SL-PAMPA permeation of tetracyclines (mean $\pm S D, n=3-6$ ).

Molecular speciation analysis was performed to elucidate the effect of $\mathrm{Ca}^{2+}$ and $\mathrm{Mg}^{2+}$ on the SL- PAMPA permeation of tetracyclines. The details of molecular speciation analysis have been reported by Werner et al [39]. Tetracyclines and divalent metal ions can form a chelate with various stoichiometries $(2: 1,1: 1,1: 2)$, depending on the ionization state of tetracyclines and metal ion species $[17,40-44]$. In this analysis, macro $\mathrm{p} K_{\mathrm{a}}$ and major molecular species are considered $[45,46]$. The fraction of each molecular species $\left(\mathrm{L}^{0}, \mathrm{~L}^{-1}, \mathrm{~L}^{-2}\right.$, $\mathrm{M}^{2+} \mathrm{L}^{-1}, \mathrm{M}^{2+} \mathrm{L}^{-2}: \mathrm{L}=$ tetracyclines, $\mathrm{M}=$ metal) (Figure 3) was calculated from the $\mathrm{p} K_{\mathrm{a}}$ values and the metal ion 
association constants $\left(K_{\mathrm{ML}}=\left[\mathrm{L}^{2} \mathrm{M}^{2+}\right] /\left(\left[\mathrm{M}^{2+}\right]\left[\mathrm{L}^{2}\right], \mathrm{z}=-1,-2\right)\right.$ of tetracyclines (Tables 1 and 2$)[17,39,47]$. In the neutral $\mathrm{pH}$ region, tetracyclines mainly exist as an equilibrium between a charge-neutral form $\left(\mathrm{L}^{0}\right)$, and negatively charged forms $\left(L^{-1}, L^{-2}\right)$ (Figure 3) $[31,40,47]$. Even though $L^{0}$ does not bind to the metal ions [47], $\mathrm{Ca}^{2+}$ and $\mathrm{Mg}^{2+}$ reduce the fraction of $\mathrm{L}^{0}\left(f_{\mathrm{LO}}\right)$ at $\mathrm{pH} 6.5$ by shifting the equilibrium (Table 3 ). The reduction of $f_{\mathrm{L} 0}$ corresponded to that of $P_{\mathrm{e}}$, except for the $\mathrm{Ca}^{2+}$ effect on OXY permeability, suggesting that the SLPAMPA membrane is impermeable to $\mathrm{M}^{2+} \mathrm{L}^{-1}$. The $\mathrm{pH}-P_{\mathrm{e}}$ relationship in our previous study [30] suggested that $\mathrm{TC}^{0}$, but not $\mathrm{TC}^{-1}$, predominantly permeates the SL-PAMPA membrane. However, further investigation is needed to better understand the effect of metal ions on tetracycline membrane permeation. The $K_{\mathrm{ML}}$ values reported in the literature show large variation $[17,39,47]$. The $f_{L O}$ value is especially sensitive to the $K_{\mathrm{ML}}$ value of $\mathrm{M}^{2+} \mathrm{L}^{-1}$. In addition, $\mathrm{M}^{2+} \mathrm{L}^{-1}$ chelates may have different stoichiometry $(1: 1$ or $1: 2)[17,39,47]$. Micro speciation with micro $\mathrm{p} K_{\mathrm{a}}$ values is required to decouple the contributions of uncharged and zwitterionic forms in $\mathrm{L}^{0}[45]$.

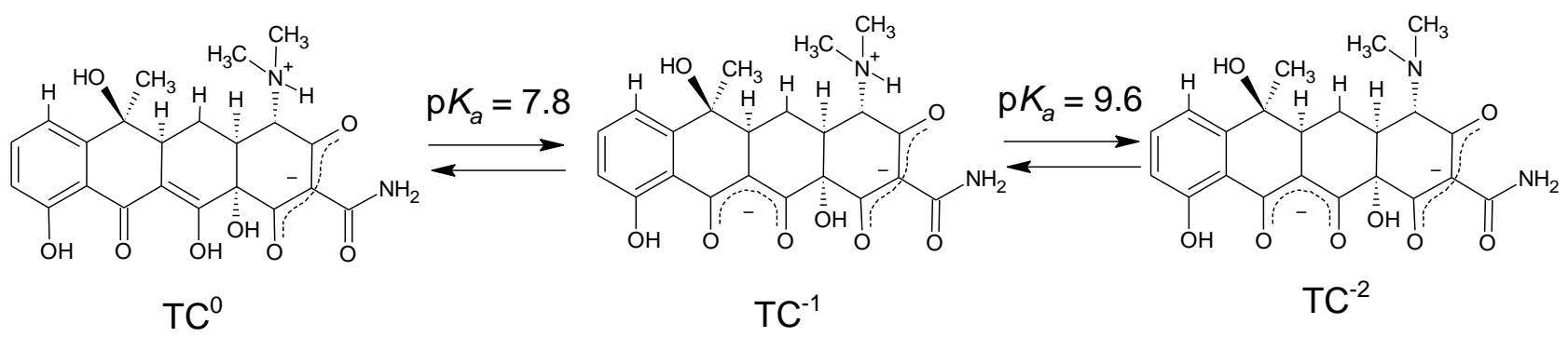

Figure 3 Ionization states of tetracycline (TC) at the neutral $\mathrm{pH}$ region. The macro $\mathrm{p} K_{a}$ value and major molecular species are shown in this figure.

Table 2. Association constants of $\mathrm{Ca}^{2+}$ and $\mathrm{Mg}^{2+}$ with tetracyclines $(\mathrm{L}=\mathrm{TC}, \mathrm{CTC}$, or $\mathrm{OXY})$

\begin{tabular}{cccc}
\hline & \multicolumn{3}{c}{$\log K_{\mathrm{ML}}$} \\
\cline { 2 - 4 } Reactions & $\mathrm{TC}$ & $\mathrm{CTC}$ & $\mathrm{OXY}$ \\
\hline $\mathrm{Ca}^{2+}+\mathrm{L}^{-1} \rightleftarrows \mathrm{Ca}^{2+} \mathrm{L}^{-1}$ & $3.4^{\mathrm{a}}, 3.0^{\mathrm{b}}$ & $3.8^{\mathrm{c}}, 2.9^{\mathrm{b}}$, & $2.9^{\mathrm{b}}$ \\
$\mathrm{Ca}^{2+}+\mathrm{L}^{-2} \rightleftarrows \mathrm{Ca}^{2+} \mathrm{L}^{-2}$ & $5.8^{\mathrm{a}}, 4.0^{\mathrm{b}}$ & $5.9^{\mathrm{c}}, 3.9^{\mathrm{b}}$, & $3.8^{\mathrm{b}}, 4.9^{\mathrm{c}}$ \\
$\mathrm{Mg}^{2+}+\mathrm{L}^{-1} \rightleftarrows \mathrm{Mg}^{2+} \mathrm{L}^{-1}$ & $3.9^{\mathrm{a}}, 3.5^{\mathrm{b}}$ & $3.3^{\mathrm{c}}, 3.2^{\mathrm{b}}$ & $3.3^{\mathrm{b}}$ \\
$\mathrm{Mg}^{2+}+\mathrm{L}^{-2} \rightleftarrows \mathrm{Mg}^{2+} \mathrm{L}^{-2}$ & $4.1^{\mathrm{a}}, 4.2^{\mathrm{b}}$ & $4.7^{\mathrm{c}}, 4.1^{\mathrm{b}}$ & $4.3^{\mathrm{b}}, 5.2^{\mathrm{c}}$ \\
\hline${ }^{\mathrm{a}}$ Ref. [39] & & & \\
${ }^{\mathrm{b}}$ Ref. [47] & & & \\
${ }^{\mathrm{c}}$ Ref. [17] & & &
\end{tabular}

In OCT-PAMPA, $\mathrm{Ca}^{2+}$ increased the $P_{e}$ values of TC, CTC, and DMCTC (Figure 4). This result is in good agreement with the previous studies investigating the $\mathrm{Ca}^{2+}$ effect on the alcohol - water partition coefficient of TC (octanol and isopentanol) [21-23]. Interestingly, $\mathrm{Ca}^{2+}$ affected SL-PAMPA and OCTPAMPA in the opposite direction for TC, CTC, and DMCTC, but in the same direction for DOXY, OTC, and MINO. On the other hand, $\mathrm{Mg}^{2+}$ decreased the $P_{e}$ values of all tetracyclines in OCT-PAMPA except for CTC (no effect). These results suggest that it could be inappropriate to use octanol as a surrogate of a phospholipid membrane for investigating the effect of divalent metal ions. In OCT-PAMPA, the octanol phase could contain water molecules in reverse micelle structures [48]. This may facilitate the permeation of charged species, such as the TC - metal chelates. In similar to SL-PAMPA, the addition of mucin did not affect the $P_{e}$ values in OCT-PAMPA, suggesting that there is no interaction between tetracyclines and mucin. As expected, there is a good correlation between $\log D_{\text {oct }}$ and $\log P_{e}$ in OCT-PAMPA (Figure 5) $[35,36]$. 
Table 3. Fraction of molecular species at $\mathrm{pH} 6.5^{\mathrm{a}}$

\begin{tabular}{|c|c|c|c|c|c|c|c|c|}
\hline \multirow{2}{*}{$\begin{array}{c}\text { Tetracyclines } \\
\text { (L) }\end{array}$} & \multirow{2}{*}{$\begin{array}{l}\text { Metal ions } \\
\text { (M) }\end{array}$} & \multicolumn{5}{|c|}{ Fraction of molecular species ${ }^{b}$} & \multicolumn{2}{|c|}{ Reduction \% } \\
\hline & & $L^{0}$ & $\mathrm{~L}^{-1}$ & $\mathrm{~L}^{-2}$ & $M^{2+}-L^{-1}$ & $M^{2+}-L^{-2}$ & $f_{L O}$ & $P_{e}$ \\
\hline \multirow[t]{3}{*}{ TC } & None & 0.95 & 0.05 & $<0.01$ & $-{ }^{c}$ & - & - & - \\
\hline & $C a^{2+d, e}$ & 0.55 & 0.03 & $<0.01$ & 0.35 & 0.07 & 42 & 35 \\
\hline & $\mathrm{Mg}^{2+\mathrm{d}, \mathrm{e}}$ & 0.33 & 0.02 & $<0.01$ & 0.65 & $<0.01$ & 65 & 67 \\
\hline \multirow[t]{3}{*}{ CTC } & None & 0.93 & 0.07 & $<0.01$ & - & - & - & - \\
\hline & $C a^{2+d, e}$ & 0.24 & 0.02 & $<0.01$ & 0.61 & 0.12 & 74 & 64 \\
\hline & $\mathrm{Mg}^{2+\mathrm{d}, \mathrm{e}}$ & 0.53 & 0.04 & $<0.01$ & 0.42 & 0.02 & 43 & 56 \\
\hline \multirow[t]{3}{*}{ OXY } & None & 0.91 & 0.09 & $<0.01$ & - & - & - & - \\
\hline & $C a^{2+d, e}$ & 0.66 & 0.07 & $<0.01$ & 0.26 & $<0.01$ & 27 & 61 \\
\hline & $\mathrm{Mg}^{2+\mathrm{d}, \mathrm{e}}$ & 0.47 & 0.05 & $<0.01$ & 0.47 & 0.02 & 49 & 64 \\
\hline
\end{tabular}

${ }^{a}$ Activity coefficients were assumed to be 1 . See ref. [39] for details; ${ }^{b} \mathrm{~L}=\mathrm{TC}, \mathrm{CTC}$, or OXY. M = Ca or Mg; ${ }^{\mathrm{C}}$ Not applicable;

${ }^{d} 5.0 \times 10^{-3} \mathrm{~mol} / \mathrm{L} ;{ }^{e}$ The $K_{\mathrm{ML}}$ values were from Ref. [39], [17], [47] for TC, CTC, and OYX, respectively.

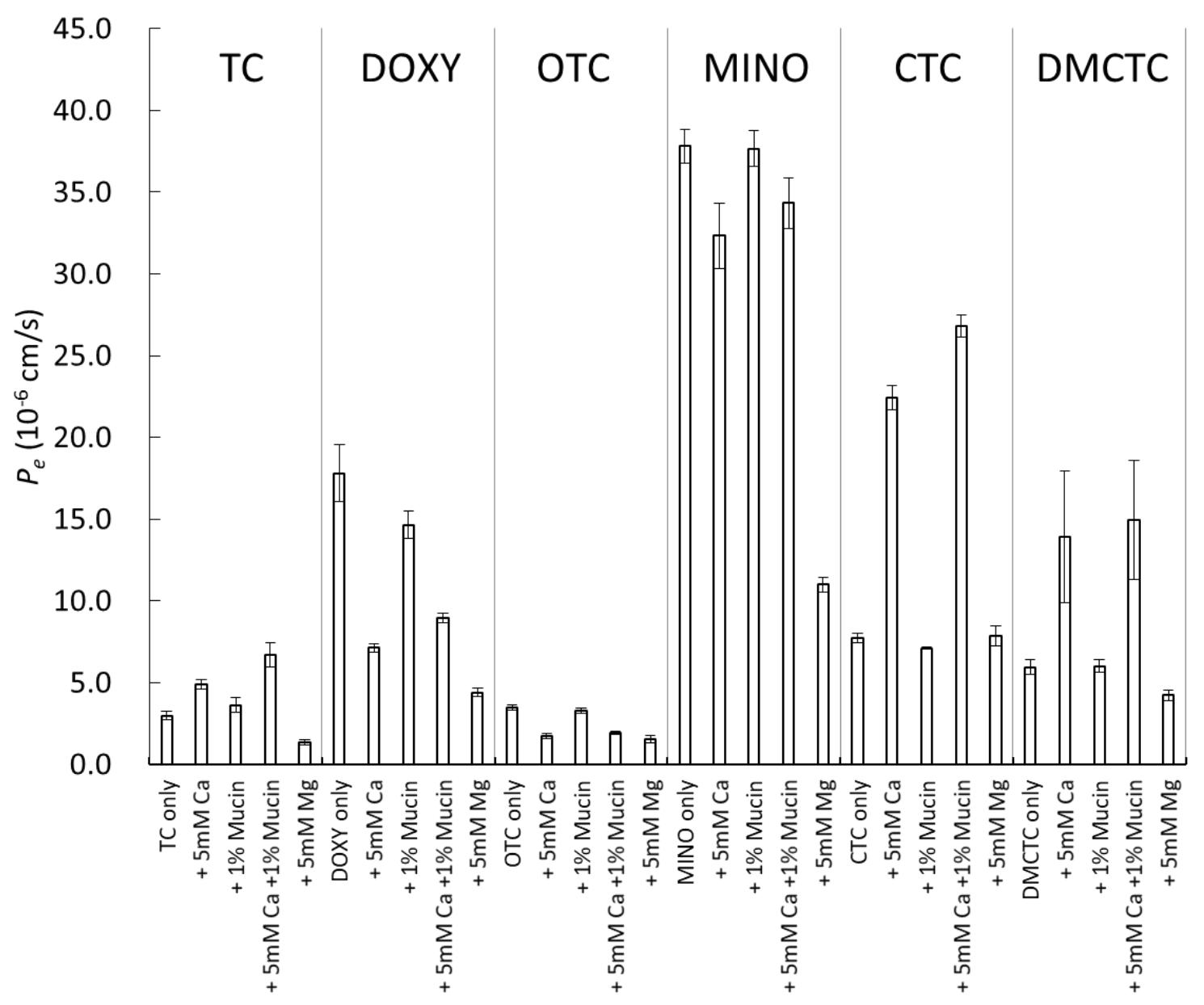

Figure 4. Effect of additives on OCT-PAMPA permeation of tetracyclines (mean $\pm S D, n=3-6$ ). 


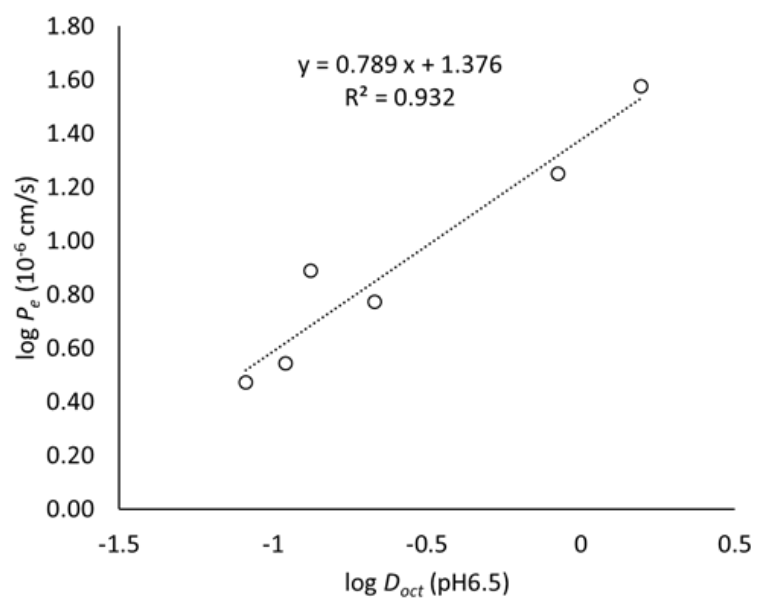

Figure 5. Correlation between $\log D_{\text {oct }}$ and $\log P_{\mathrm{e}}$ of tetracyclines in OCT-PAMPA. The $\log D_{\text {oct }}$ values were taken from the literatrue [30].

Clinically, co-administration of food and milk has been reported to decrease the bioavailability of tetracyclines (Table 4) [4-10]. The effect of food and milk on bioavailability is greater for TC and OXY, but relatively small for DOXY and MINO [4]. However, in the present study, the percent reduction of $P_{\mathrm{e}}$ by $\mathrm{Ca}^{2+}$ was smallest for TC (MINO (87 \%) > DMCTC $(67 \%) \approx \operatorname{CTC}(64 \%) \approx \operatorname{DOXY}(62 \%) \approx \operatorname{OXY}(61 \%)>\operatorname{TC}(35 \%)$ ). The $P_{\mathrm{e}}$ values of MINO and DOXY are higher than that of the other tetracyclines. In addition, after oral administration, MINO and DOXY are almost completely absorbed, whereas TC, OXY, CTC and DMCTC are incompletely absorbed [4]. Therefore, the reduction of $P_{\mathrm{e}}$ by $\mathrm{Ca}^{2+}$ may have less impact on the bioavailability of MINO and DOXY. Barza et al. reported that, after the administration of tetracyclines with milk into the ileal loop in dogs, the remaining fraction in the luminal contents is DOXY >> OXY $\approx$ MINO $\approx$ TC [49]. Lipophilicity may play a role in food and milk binding. The balance of metal ion chelating, food/ milk binding, and membrane permeation may determine the extent of food and milk effects. Interestingly, the effects of metal ions and $\mathrm{pH}$ [30] on the bioavailability of TC to E.coli are similar to that on SL-PAMPA permeation [50].

Table 4. Summary of food and milk effects on bioavailability of tetracyclines

\begin{tabular}{|c|c|c|c|c|}
\hline \multirow{2}{*}{ Drugs } & \multirow{2}{*}{$\begin{array}{c}\text { Percentage } \\
\text { absorption, } \%^{\mathrm{a}}\end{array}$} & \multicolumn{2}{|c|}{ Bioavailability reduction, $\%^{b}$} & \multirow{2}{*}{$\begin{array}{c}\text { References for food } \\
\text { and milk effect }\end{array}$} \\
\hline & & Food & Milk & \\
\hline СТC & $25-30$ & $45^{c}$ & $N A^{d}$ & [9] \\
\hline DМСтC & 66 & $N A^{d}$ & 70 & [6] \\
\hline DOXY & 95 & $26(3-49)$ & $30(9-53)$ & {$[10]$} \\
\hline MINO & $95-100$ & $14(2-51)$ & $27(8-61)$ & {$[6,9,10]$} \\
\hline OXY & 58 & $41(4-77), 0^{c, e}$ & $83(45-96)$ & {$[6,9,10]$} \\
\hline TC & $77-88$ & $46(13-73 \%), 72^{c}$ & 65 & {$[5,8-10]$} \\
\hline
\end{tabular}

We could not find any plausible chemical structural elucidation for the differences among tetracyclines regarding the effects of $\mathrm{Ca}^{2+}$ and $\mathrm{Mg}^{2+}$. Tetracyclines can easily modify their tautomerism in response to various chemical environments [44]. Metal binding to anionic phospholipids in the SL-PAMPA membrane may be another possible mechanism to reduce the permeation of tetracyclines. In our previous study, the addition of an anionic lipid neutralizer (tetrahexylammonium) did not affect the permeation of TC in SLPAMPA, suggesting that the ionic interaction with anionic phospholipids do not facilitate the permeation of 
TC [30]. Further investigation is required to clarify the interactions among tetracyclines, metal ions, and phospholipids. We are currently investigating the effects of metal ions on the SL-PAMPA permeation of structurally diverse drugs.

\section{Conclusion}

In contrast to the previously suggested mechanism [21,22], in this study, $\mathrm{Ca}^{2+}$ chelate formation decreased the membrane permeation of tetracyclines, irrespective of $\mathrm{Ca}^{2+}$ linked mucin binding. $\mathrm{Ca}^{2+}$ affected the $P_{\mathrm{e}}$ values in SL-PAMPA and OCT-PAMPA in the opposite direction for some tetracyclines. SLPAMPA can be a simple tool to qualitatively evaluate the effect of multivalent metal ions on the membrane permeation of drugs.

Conflict of interest: The authors declare no conflict of interest.

\section{References}

[1] B.M. Lomaestro, G.R. Bailie. Absorption interactions with fluoroquinolones. Drug Saf. 12 (1995) 314333.

[2] R. Krishna, L. East, P. Larson, C. Valiathan, K. Butterfield, Y. Teng, M. Hernandez-Illas. Effect of metalcation antacids on the pharmacokinetics of $1200 \mathrm{mg}$ raltegravir. J. Pharm. Pharmacol. 68 (2016) 1359-1365.

[3] D.D. Williams, B. Peng, C.K. Bailey, M.B. Wire, Y. Deng, J.W. Park, D.A. Collins, S.G. Kapsi, J.M. Jenkins. Effects of food and antacids on the pharmacokinetics of eltrombopag in healthy adult subjects: Two single-dose, open-label, randomized-sequence, crossover studies. Clin. Ther. 31 (2009) 764-776.

[4] K.N. Agwuh, A. MacGowan. Pharmacokinetics and pharmacodynamics of the tetracyclines including glycylcyclines. J. Antimicrob. Chemother. 58 (2006) 256-265.

[5] H. Jung, A.A. Peregrina, J.M. Rodriguez, R. Moreno-Esparza. The influence of coffee with milk and tea with milk on the bioavailability of tetracycline. Biopharm. Drug Dispos. 18 (1997) 459-463.

[6] J.J. Leyden. Absorption of minocycline hydrochloride and tetracycline hydrochloride: effect of food, milk, and iron. J. Am. Acad. Dermatol. 12 (1985) 308-312.

[7] Bioavailability of tetracycline and doxycycline in fasted and nonfasted subjects. Antimicrob. Agents Chemother. 11 (1977) 462-469.

[8] H.J. Cook, C.R. Mundo, L. Fonseca. Influence of the diet on bioavailability of tetracycline. Biopharm. Drug Dispos. 14 (1993) 549-553.

[9] P. Nielsen, N. Gyrd-Hansen. Bioavailability of oxytetracycline, tetracycline and chlortetracycline after oral administration to fed and fasted pigs. J. Vet. Pharmacol. Ther. 19 (1996) 305-311.

[10] F.P. Meyer. Minocycline for acne. Food reduces minocycline's bioavailability. BMJ Br. Med. J. 312 (1996) 1101.

[11] P.J. Neuvonen. Interactions with the absorption of tetracyclines. Drugs. 11 (1976) 45-54.

[12] A.H. Caswell, J.D. Hutchison. Selectivity of cation chelation to tetracyclines: evidence for special conformation of calcium chelate. Biochem. Biophys. Res. Commun. 43 (1971) 625-630.

[13] K.W. Kohn. Mediation of divalent metal ions in the binding of tetracycline to macromolecules. Nature 191 (1961) 1156-1158.

[14] L. Lambs, B. Decock-Le Reverend, H. Kozlowski, G. Berthon. Metal ion-tetracycline interactions in biological fluids. 9. Circular dichroism spectra of calcium and magnesium complexes with tetracycline, oxytetracycline, doxycycline, and chlortetracycline and discussion of their binding modes. Inorg. Chem. 27 (1988) 3001-3012.

[15] J.T. Doluisio, A.N. Martin. Metal complexation of the tetracycline hydrochlorides. J. Med. Chem. 6 (1963) 16-20. 
[16] M.O. Schmitt, S. Schneider. Spectroscopic investigation of complexation between various tetracyclines and Mg 2+ or Ca 2+. PhysChemComm. 3 (2000) 42-55.

[17] R. Pulicharla, K. Hegde, S.K. Brar, R.Y. Surampalli. Tetracyclines metal complexation: Significance and fate of mutual existence in the environment. Environ. Pollut. 221 (2017) 1-14.

[18] S. Banerjee, K. Chakrabarti. The transport of tetracyclines across the mouse ileum in vitro: the effect of cations and other agents. J. Pharm. Pharmacol. 28 (1976) 133-138.

[19] H. Poiger, C. Schlatter. Interaction of cations and chelators with the intestinal absorption of tetracycline. Naunyn. Schmiedebergs. Arch. Pharmacol. 306 (1979) 89-92.

[20] L. V Allen Jr, R.S. Levinson, C. Robinson, A. Lau. Effect of surfactant on tetracycline absorption across everted rat intestine. J. Pharm. Sci. 70 (1981) 269-271.

[21] K. Kakemi, H. Sezaki, H. Ogata, T. Nadai. Absorption and excretion of drugs. XXXVI. Effect of Ca2+ on the absorption of tetracycline from the small intestine (1). Chem. Pharm. Bull. 16 (1968) 2200-2205.

[22] K. Kakemi, H. Sezaki, M. Hayashi, T. Nadai. Absorption and excretion of drugs. XXXVII. Effect of Ca2+ on the absorption of tetracycline from the small intestine (2). Chem. Pharm. Bull. 16 (1968) 22062212.

[23] G.E. Schumacher, E.E. Linn. Kinetic and thermodynamic aspects of in vitro interphase transfer of tetracyclines II: Influence of divalent metal salts. J. Pharm. Sci. 67 (1978) 1717-1720.

[24] P.L. Nicklin, W.J. Irwin, I.F. Hassan, M. Mackay. Development of a minimum-calcium Caco-2 monolayer model: calcium and magnesium ions retard the transport of pamidronate. Int. J. Pharm. 123 (1995) 187-197.

[25] D. El-Sabawi, R. Abu-Dahab, W.A. Zalloum, F. ljbara, I.I. Hamdan. The effect of ferrous ions, calcium ions and citric acid on absorption of ciprofloxacin across caco-2 cells: practical and structural approach. Drug Dev. Ind. Pharm. 45 (2019) 292-303.

[26] M. Kansy, F. Senner, K. Gubernator. Physicochemical high throughput screening: parallel artificial membrane permeation assay in the description of passive absorption processes. J. Med. Chem. 41 (1998) 1007-1010.

[27] K. Sugano, H. Hamada, M. Machida, H. Ushio. High throughput prediction of oral absorption: Improvement of the composition of the lipid solution used in parallel artificial membrane permeation assay. J. Biomol. Screen. 6 (2001) 189-196.

[28] K. Sugano, M. Kansy, P. Artursson, A. Avdeef, S. Bendels, L. Di, G.F. Ecker, B. Faller, H. Fischer, G. Gerebtzoff, H. Lennernaes, F. Senner. Coexistence of passive and carrier-mediated processes in drug transport. Nat. Rev. Drug Discov. 9 (2010) 597-614.

[29] A. Avdeef, S. Bendels, L. Di, B. Faller, M. Kansy, K. Sugano, Y. Yamauchi. PAMPA - Critical factors for better predictions of absorption. J. Pharm. Sci. 96 (2007) 2893-2909.

[30] S. Yamauchi, K. Sugano. Permeation characteristics of tetracyclines in parallel artificial membrane permeation assay. ADMET DMPK 7 (2019) 151-160.

[31] S. Babić, A.J.M. Horvat, D. Mutavdžić Pavlović, M. Kaštelan-Macan. Determination of pKa values of active pharmaceutical ingredients. TrAC - Trends Anal. Chem. 26 (2007) 1043-1061.

[32] S. Şanli, N. Şanli, G. Alsancak. Determination of protonation constants of some tetracycline antibiotics by potentiometry and LC methods in water and acetonitrile-water binary mixtures. $J$. Braz. Chem. Soc. 20 (2009) 939-946.

[33] PMDA. Minocycline hydrochloride Drug product information. (2011). https://www.info.pmda.go.jp/igo/pack/6152005F1052 2 11/.

[34] A. Avdeef. Absorption and Drug Development: Solubility, Permeability, and Charge State, Second Edition, John Wiley \& Sons, Inc., 2012.

[35] B. Faller, H.P. Grimm, F. Loeuillet-Ritzler, S. Arnold, X. Briand. High-throughput lipophilicity measurement with immobilized artificial membranes. J. Med. Chem. 48 (2005) 2571-2576.

[36] Z. Song, K. Terada, K. Sugano. Reversed phase parallel artificial membrane permeation assay for log P measurement. ADMET DMPK 4 (2016) 54-59. 
[37] MHLW. Overview of Dietary Reference Intakes for Japanese (2015), 2015. https://www.mhlw.go.jp/file/06-Seisakujouhou-10900000-Kenkoukyoku/Overview.pdf.

[38] C. Schiller, C.P. Fröhlich, T. Giessmann, W. Siegmund, H. Mönnikes, N. Hosten, W. Weitschies. Intestinal fluid volumes and transit of dosage forms as assessed by magnetic resonance imaging. Aliment. Pharmacol. Ther. 22 (2005) 971-979.

[39] J.J. Werner, W.A. Arnold, K. McNeill. Water hardness as a photochemical parameter: tetracycline photolysis as a function of calcium concentration, magnesium concentration, and pH. Environ. Sci. Technol. 40 (2006) 7236-7241.

[40] L. Jin, X. Amaya-Mazo, M.E. Apel, S.S. Sankisa, E. Johnson, M.A. Zbyszynska, A. Han. Ca2+ and Mg2+ bind tetracycline with distinct stoichiometries and linked deprotonation. Biophys. Chem. 128 (2007) 185-196.

[41] D.C. Maxwell, P.J.A. Smith, S.P. Wilford. Stabilities of some alkaline earth chelates of tetracycline. Nature 198 (1963) 577-578.

[42] L.Z. Benet, J.E. Goyan. Thermodynamics of chelation by tetracyclines. J. Pharm. Sci. 55 (1966) 11841190.

[43] M. Novák-Pékli, M.E.-H. Mesbah, G. Pethö. Equilibrium studies on tetracycline-metal ion systems. J. Pharm. Biomed. Anal. 14 (1996) 1025-1029.

[44] H.A. Duarte, S. Carvalho, E.B. Paniago, A.M. Simas. Importance of tautomers in the chemical behavior of tetracyclines. J. Pharm. Sci. 88 (1999) 111-120.

[45] A. Pagliara, P.A. Carrupt, G. Caron, P. Gaillard, B. Testa. Lipophilicity profiles of ampholytes. Chem. Rev. 97 (1997) 3385-3400.

[46] H. Terada, T. Inagi. Proposed partition mechanism of tetracycline. Chem. Pharm. Bull. 23 (1975) 1960-1968.

[47] S.R. Martin. Equilibrium and kinetic studies on the interaction of tetracyclines with calcium and magnesium. Biophys. Chem. 10 (1979) 319-326.

[48] N.P. Franks, M.H. Abraham, W.R. Lieb. Molecular organization of liquid n-octanol: An X-ray diffraction analysis. J. Pharm. Sci. 82 (1993) 466-470.

[49] M. Barza, R.B. Brown, C. Shanks, C. Gamble, L. Weinstein. Relation Between Lipophilicity and Pharmacological Behavior of Minocycline, Doxycycline, Tetracycline, and Oxytetracycline in Dogs. Antimicrob. Agents Chemother. 8 (1975) 713-720.

[50] Y. Zhang, S.A. Boyd, B.J. Teppen, J.M. Tiedje, H. Li. Role of tetracycline speciation in the bioavailability to Escherichia coli for uptake and expression of antibiotic resistance. Environ. Sci. Technol. 48 (2014) 4893-4900.

C 2020 by the authors; licensee IAPC, Zagreb, Croatia. This article is an open-access article distributed under the terms and conditions of the Creative Commons Attribution license (http://creativecommons.org/licenses/by/3.0/) (cc) B EY 